\title{
Propagação vegetativa de Sinningia lineata (Hjelmq.) Chautems, rainha-do-abismo ${ }^{(1)}$
}

\author{
CECÍLIA MACIEL BARROSO(2), INGRID B.I. DE BARROS(3), LÚCIA BRANDÃO FRANKE(4), \\ BRUNISLAU GLOVACKI(5) e MÁRIO LUIS FOCHESATO(6)
}

\begin{abstract}
RESUMO
Sinningia lineata (Hjelmq.) Chautems tem grande potencial ornamental. Apesar de sua rusticidade, esta espécie encontrase ameaçada de extinção em virtude dos impactos ocorridos em seu ambiente. Em se tratando de recursos genéticos, os estudos de propagação vegetativa contribuem para a manutenção da variabilidade genética em bancos de germoplasma considerados importantes por para viabilizar o uso de espécies na ornamentação e paisagismo. Com o propósito de criar subsídios para tais práticas, o objetivo deste trabalho foi testar métodos de propagação vegetativa de $S$. lineata. Foram desenvolvidos dois estudos: a propagação por divisão de tubérculos e por estaquia. No primeiro, selecionaram-se 36 tubérculos distribuídos em nove tratamentos com quatro repetições. Os tratamentos constaram de três testemunhas, três com aplicação de calda bordalesa e três com aplicação de calda sulfocálcica. Os três tratamentos para cada aplicação referem-se às secções dos tubérculos em 2, 3 e 4 fragmentos. Avaliaram-se a capacidade de cicatrização dos fragmentos e a produção de novos indivíduos. No experimento de propagação por estaquia, foram utilizadas 51 estacas herbáceas com um par de folhas. Os três tratamentos com 17 repetições foram os seguintes: testemunha, aplicação de 100 e de 200 ppm de ácido indolbutírico (AIB). Foram avaliados seis parâmetros referentes ao desenvolvimento de brotações, tubérculos e raízes. Os resultados do primeiro estudo indicaram não haver diferença em relação à cicatrização dos fragmentos dos tubérculos e à aplicação dos fungicidas. No entanto, nos tratamentos com a divisão em quatro fragmentos, ocorreram perdas por desidratação de, em média, 75, 100 e 50\% dos fragmentos referentes ao tratamento testemunha e aos tratamentos com aplicação de calda bordalesa e de calda sulfocálcica respectivamente. Ao final do segundo estudo, todas as estacas mostraram-se viáveis e deram origem a novos indivíduos. Todavia, a utilização de AIB sugeriu um efeito fitotóxico sobre as estacas de $S$. lineata. Os resultados dos dois estudos indicaram ser a espécie facilmente propagada assexuadamente. Os métodos revelaram-se viáveis em relação aos custos e à simplicidade das técnicas.
\end{abstract}

Palavras-chave: espécie ornamental, estaquia, divisão de tubérculo, calda bordalesa, calda sulfocálcica.

ABSTRACT

Vegetative propagation of Sinningia lineata (Hjelmq.) Chautems

\begin{abstract}
Sinningia lineata (Hjelmq.) Chautems has great ornamental potentiality. In spite of its rusticity, this species is in danger of extinction due to the impacts that occurred on its natural habitat. Concerning the genetic resources, the studies with vegetative propagation contribute to the maintenance of the genetic variability in germplasm banks. These are also important to make viable the use of the species in ornamentation and landscaping. This study aims to creat subsidies for these practices, by testing vegetative propagation methods of $S$. lineata. Two studies were undertaken, propagation via tubercle division and via staking. In the first, 36 tubercles were selected and distributed in nine treatments with four repetitions. The treatments consisted of three controls, three with the bordeaux syrup and three with the sulphurcalcic syrup. The three treatments for each application refer to the tubercle sections in 2, 3, and 4 fragments. The capacity for cicatrisation of the fragments and the production of new exemplars were evaluated. The stakes received three treatments with 17 repetitions, as follows: control, application of 100 and of $200 \mathrm{ppm}$ of indolbutyric acid (IBA). Six parameters were evaluated referring to the development of sprouts, tubercles and roots. The results of the first study indicated that no difference occurred in relation to cicatrisation of the tubercle fragments and the application of fungicides. However, under the treatments with the division in four fragments, losses occurred by dehydration on average, 75,100 and $50 \%$ of the fragments referring to the controlled treatment and the ones with the application of bordeaux and sulphurcalcic syrup, respectively. At the end of the second study, all the stakes were viable and originated new exemplars. Nevertheless, the use of IBA suggested a phytotoxic effect on the $S$. lineata stem. The results of the two studies indicated that the species is easily asexually propagated. The methods proved to be viable in relation to cost and simplicity of the techniques.
\end{abstract}

Keywords: ornamental species, stem propagation, tubercle division, bordeaux and sulphurcalcic syrup

(') Parte da Dissertação de Mestrado da primeira autora, apresentada na Universidade Federal do Rio Grande do Sul - UFRGS. Trabalho financiado pela CAPES. Recebido para publicação em 04/07/2007 e aceito em 27/03/2008

${ }^{(2)}$ Bióloga, M.Sc., em Fitotecnia/Horticultura, UFRGS, Porto Alegre (RS).; Analista Ambiental do Sistema de Proteção da Amazônia (SIPAM), Manaus (AM).E-mail: ceciliabarroso@hotmail.com; cecília.barroso@sipam.gov.br

(3) Engenheira Agrônoma, Professora da Faculdade de Agronomia da UFRGS.E-mail: ingridb@ufrgs.br; lbfranke@ufrgs.br

$\left({ }^{4}\right)$ Engenheiro-Agrônomo, Jardim Botânico de Porto Alegre, Porto Alegre (RS). E-mail: bruno.glovacki@fzb.rs.gov.br

$\left({ }^{5}\right)$ Engenheiro Agrônomo, M.Sc., em Fitotecnia pela Faculdade de Agronomia da UFRGS. E-mail: mariofochesato@ig.com.br 


\section{INTRODUÇÃO}

As principais propostas e iniciativas para a utilização ornamental de espécies nativas referem-se às espécies arbóreas e poucos são os trabalhos e tentativas com plantas de porte herbáceo. Existe uma infinidade de espécies herbáceas com potencial para serem incluídas em práticas de ornamentação e paisagismo. Talvez por razões culturais ou por falta de uma visão mais ampla sobre novas possibilidades, essas plantas raramente são associadas, lembradas ou reconhecidas como plantas que podem ser cultivadas e apreciadas pelos brasileiros.

Dentre tantos grupos botânicos nativos do Brasil pouco conhecidos popularmente, destaca-se a família Gesneriaceae Rich. \& Juss., representada por espécies com grande potencial ornamental. Sinningia lineata (Hjelmq.) Chautems, conhecida por alguns como rainhado-abismo, está na lista de espécies ameaçadas no Rio Grande do Sul (RIO GRANDE DO SUL, 2003).

$S$. lineata habita ambientes rupícolas, margens rochosas e paredões escarpados dos cursos d'água. No
Rio Grande do Sul, sua distribuição parece estar restrita à região norte, junto ao rio Uruguai e afluentes, nos municípios de Barracão (SILVEIRA, 1992), Esmeralda ${ }^{6}$, Pìnhal da Serra $^{6}$ e Vacaria ${ }^{27}$. Em Santa Catarina, há registros para os municípios de Erval Velho ${ }^{7}$, Campo Belo $^{7}$ e Lacerdópolis ${ }^{7}$. No entanto, em função da construção de barragens na Bacia do rio Uruguai, os níveis dos cursos d'água estão sendo afetados, modificando, em alguns pontos, o microambiente característico para a ocorrência desta espécie (BARROSO et al., 2002).

Trata-se de uma herbácea tuberosa de notável beleza, cujas flores atraem beija-flores, e apresentam uma variação natural no padrão de cores e manchas dos tubos florais (figura 1). Caules herbáceos brotam nos tubérculos. Estes, aos 20 anos, podem atingir entre 20 e $30 \mathrm{~cm}$ de diâmetro ${ }^{7}$ (Figura 3). A altura da planta pode alcançar até $60 \mathrm{~cm}$ (SÃO PAULO, 2006). As folhas são verdes, carnosas, pilosas e formam uma folhagem densa. Os caules herbáceos possuem ramificações apicais e a coloração é verde ou avermelhada com linhas escuras (figura 2).

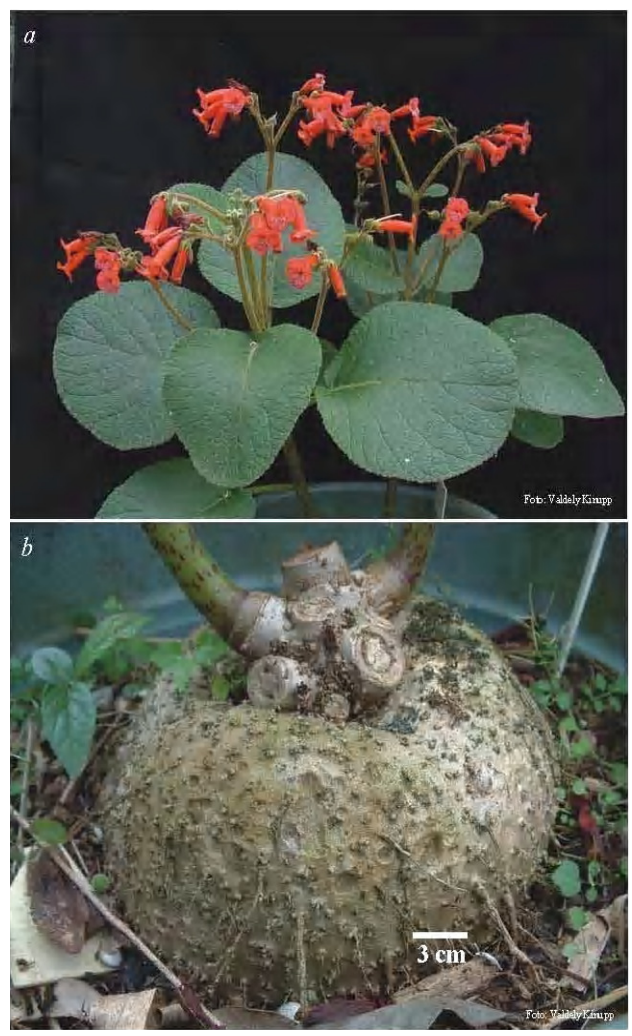

Figura 1 ( $\boldsymbol{a}, \boldsymbol{b} \boldsymbol{e} \boldsymbol{c})$ : Flores de Sinningia lineata (Hjelmq.) Chautems. Variação no padrão de cores e manchas em espécimes de populações naturais. ( $a, c$ : Rio Bernardo José, RS; $b$ : exemplar da coleção de Gesneriaceae do Jardim Botânico de Porto Alegre, coletado em Barracão, RS)

Figure 1 ( $\boldsymbol{a}, \boldsymbol{b}$ and $\boldsymbol{c})$ : Sinningia lineata (Hjelmq.) Chautems flowers. Variation in the colors and stains standard in specimens of natural populations. (a, c: Bernardo José river, RS; $b$ : copy of the collection of Gesneriaceae of the Botanical Garden of Porto Alegre, collected in Bernardo José, RS)

\footnotetext{
${ }^{6}$ Klein, G. N. (Coordenador de Pesquisa e Analista Ambiental, IBAMA/PA). Comunicação pessoal, 2005.

${ }^{7}$ Chautems, A. (Pesquisador em Taxonomia, nomenclatura e Biogeografia Neotropical no Conservatoire et Jardin botaniques de la Ville de Genève). Comunicação pessoal, 2006 e 2008.
} 


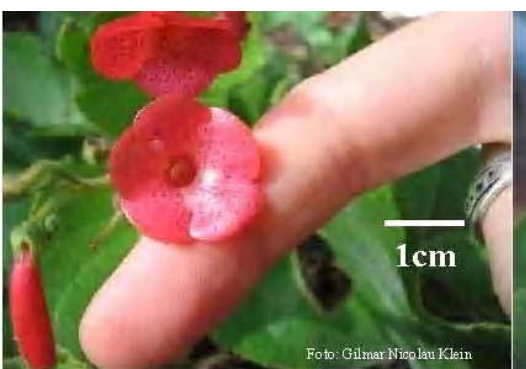

$a$

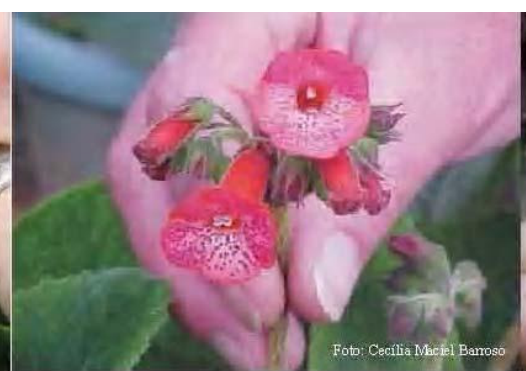

b

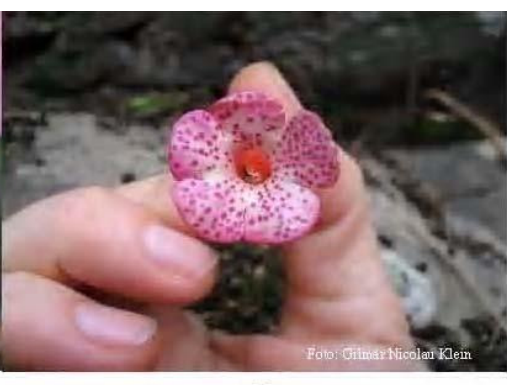

C

Figura 2 ( $\boldsymbol{a}$ e $\boldsymbol{b}$ ): Sinningia lineata (Hjelmq.) Chautems, espécime da coleção de Gesneriaceae do Jardim Botânico de Porto Alegre, RS. ( $a$ : aspecto geral das flores e folhas; $b$ : tubérculo com $20 \mathrm{~cm}$ de diâmetro)

Figure 2 ( $(\boldsymbol{a}$ and b): Sinningia lineata (Hjelmq.) Chautems, specimen of the collection of Gesneriaceae of the Botanical Garden of Porto Alegre, RS (a: general aspect of the flowers and leaves; $b$ : tuber with 20 diameter cm)

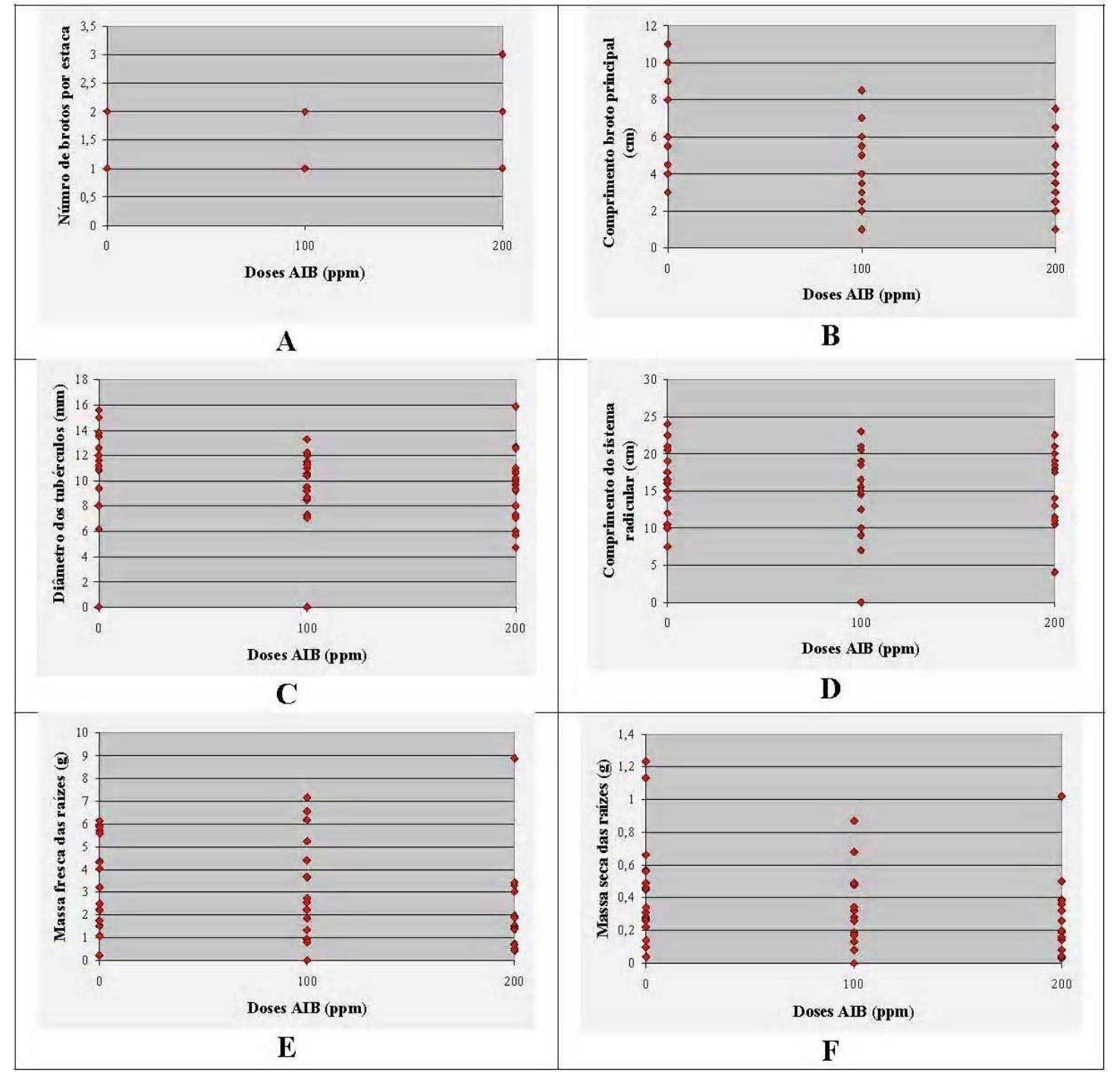

Figura 3. Dispersão dos dados referentes aos parâmetros avaliados: número de brotos (A), comprimento do broto principal (B), diâmetro dos tubérculos (C), comprimento do sistema radicular (D), massa fresca das raízes (E) e massa seca das raízes (F) em estacas de Sinningia lineata (Hjelmq.) Chautems, em função das diferentes doses de AIB.

Figure 3. Dispersion of the referring data to the evaluated parameters: number of sprouts (A), length of the main sprout $(B)$, diameter of the tubers $(C)$, length of the system radicular $(D)$, fresh mass of the roots $(E)$ and drought mass of the roots $(F)$ in Sinningia lineata (Hjelmq.) Chautems cuttings, in function of the different AIB's doses. 
As demais espécies de Sinningia também possuem caules herbáceos e tubérculos, alguns com maiores dimensões (tubérculos de $S$. macrostachya (Lindl.) Chautems podem chegar a $1 \mathrm{~m}$ de diâmetro). Experimentos para estabelecer protocolos de propagação vegetativa para $S$. lineata têm grandes possibilidades de serem eficientes para elucidar a propagação de suas congêneres. A rusticidade dessa espécie rupestre indica a facilidade para o manejo. A floração, persistente e subseqüente, é um indicativo adicional à sua adequação no mercado paisagístico.

Quando se trata da propagação de espécies nativas para o uso ornamental e paisagístico, diminui-se o risco da contaminação biológica _pelo escape de plantas das áreas de cultivo, e a propagação em viveiros legalizados diminui a pressão por coletas na natureza. Para o uso de plantas nativas raras ou ameaçadas de extinção, no entanto, questões como a pressão de coleta, a diversidade genética e a seleção de variedades devem ser consideradas. A experimentação e as técnicas de reprodução e cultivo são as mesmas, mas deve-se ter cuidado para não promover a erosão da variabilidade genética das populações e selecionar matrizes dos locais ou proximidades_se houver a pretensão de reintroduzilas (BARROSO et al., 2004). Experimentar técnicas de propagação de espécies nativas é de grande importância para os programas de conservação de espécies ameaçadas e para a divulgação de nosso patrimônio natural. A produção para fins comerciais é uma forma de colocar a espécie ao alcance da população, de forma a divulgar sua existência e evitar coletas na natureza. A obtenção de um número suficiente de propágulos de plantas nativas para a realização de experimentos de multiplicação, muitas vezes, representa o primeiro desafio dentro desta linha de pesquisa. A uniformidade do material utilizado nem sempre é possível.

Características de interesse e a variabilidade genética da espécie podem ser fixadas por meio da multiplicação vegetativa. O sucesso da propagação vegetativa depende, em primeira instância, da capacidade das várias partes da planta em formar novas raízes (HARTMANN e_KESTER, 1968).

O princípio da multiplicação rápida pela divisão de tubérculos baseia-se na capacidade deste órgão em formar raízes e produzir plantas normais (SILVA, 1987). A propagação de tubérculos por secção pode proporcionar o aumento não só do número de indivíduos sadios e com características genéticas de interesse, mas, também, o risco de incidência de doenças fúngicas, bacterianas e viróticas. A secção cria as condições favoráveis à contaminação por agentes patógenos, por meio da exposição de tecidos hidratados do córtex e medula ao ambiente externo, com temperaturas mais altas pelo efeito das estufas. Uma vez selecionado o material livre de patógenos, a assepsia deve ser observada para evitar sua contaminação (AVILA e BEEK, 1987).

Outro método de propagação é a estaquia, muito utilizada para a propagação comercial em estufas de plantas ornamentais. Este método apresenta muitas vantagens, como a capacidade de produção de muitas plantas em um espaço limitado, o baixo custo, a rapidez e a simplicidade (HARTMANN \& e KESTER, 1968).

Já foi demonstrado que substâncias indutoras à formação de raízes de ocorrência natural nas plantas podem ser abundantes, escassas ou mesmo ausentes dentre as espécies. O ácido indolbutírico (AIB) é a auxina sintética fitorreguladora mais utilizada para acelerar o processo de enraizamento de estacas. Existe, no entanto, a necessidade de experimentar as dosagens para cada espécie e avaliar a eficácia ou a fitotoxicidade para o enraizamento. O AIB não é tóxico em uma ampla gama de concentrações - sua ação é mais localizada do que outros produtos e apresenta maior estabilidade química no corpo da estaca (ALVARENGA e CARVALHO, 1983; IRITANI e SOARES, 1982; HARTMANN_e KESTER, 1990), em relação a outros fitorreguladores, sob condições ambientais adversas. Em espécies de difícil enraizamento, a deficiência pode estar no baixo teor de auxina. Nesse caso, é necessária uma complementação com um fitorregulador e carboidratos necessários à manutenção celular (HARTMANN e KESTER, 1968).

As estacas herbáceas com folhas necessitam de alta umidade e calor. Mesmo não sendo necessária a aplicação de substâncias que promovam o enraizamento deste tipo de estaca muitas vezes elas são utilizadas para obter a uniformidade do enraizamento e a abundância de raízes (HARTMANN e KESTER, 1968).

O substrato utilizado também influencia naqualidade e percentual de raízes formadas (COUVILLON, 1988). Ele deve fixar as estacas, manter boa aderência e permitir a remoção das plantas sem causar danos às raízes. No Brasil, a casca de arroz carbonizada, isolada ou em misturas, vem sendo utilizada há vários anos para o enraizamento de espécies ornamentais (STUMPF et al., 2001). Esse material ocupa elevado volume e possui muitos espaços para aeração, baixa densidade e alta permeabilidade à água e resistência à decomposição (BACKES, 1989; BELLÉ, 1990). A drenagem é rápida e o $\mathrm{pH}$ é em torno da neutralidade (KÄMPF, 2000; SILVA et al., 2000).

Pelo o que foi exposto, este trabalho tem como objetivos experimentar a propagação vegetativa $S$. lineata por meio da divisão de tubérculos e da estaquia e estabelecer protocolos para tais formas de propagação.

\section{MATERIAL E MÉTODOS}

O material testemunha (Voucher) está localizado no Departamento de Botânica da Universidade Federal do Rio Grande do Sul - UFRGS, identificado por ICN143626.

\subsection{Divisão de tubérculos}

$O$ experimento foi realizado em uma casa de vegetação do Jardim Botânico de Porto Alegre, na Fundação Zoobotânica do Rio Grande do Sul. O período experimental foi de outubro de 2004 a abril de 2005. Utilizaram-se tubérculos provenientes de um prévio experimento com germinação de sementes de um exemplar de $S$. lineata pertencente à coleção viva de Gesneriaceae do Jardim Botânico de Porto Alegre. 
Selecionaram-se 36 tubérculos de plantas sadias com um ano e seis meses de vida. O peso médio dos tubérculos foi de $60 \mathrm{~g}$. As médias de altura e diâmetro foram de 4,2 e 5,3 cm respectivamente. A sanidade foi visual e manualmente avaliada. As folhas e raízes foram retiradas e os tubérculos, colocados sobre bancada, onde foram lavados em água corrente, pesados e medidos quanto à altura e diâmetro. Testaram-se nove tratamentos com quatro repetições, envolvendo diferentes dimensões de cortes dos tubérculos e a aplicação ou não de fungicidas, a seguir exemplificados:

- Corte longitudinal dos tubérculos em dois fragmentos:

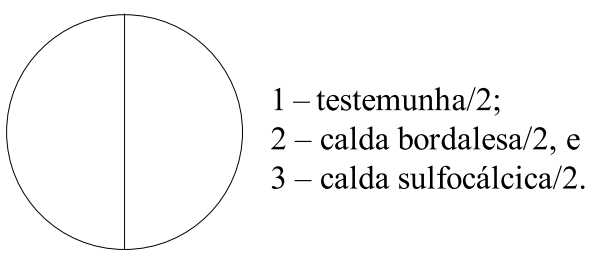

- Corte longitudinal dos tubérculos em três fragmentos:

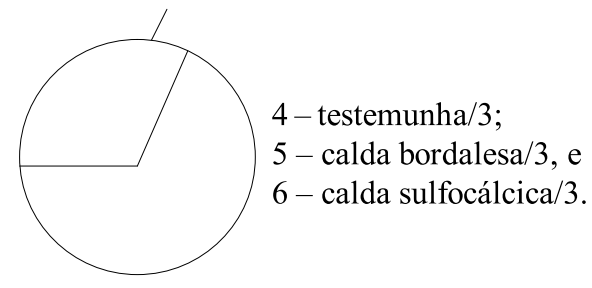

- Corte longitudinal dos tubérculos em quatro fragmentos:

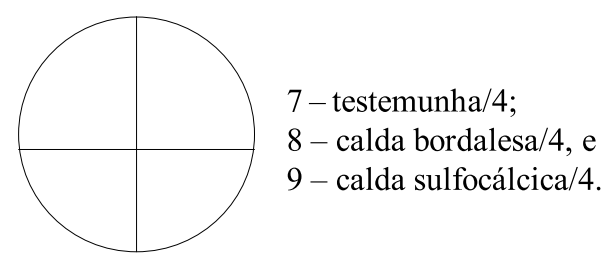

Tendo como referência a posição das gemas, efetuaram-se os cortes no sentido longitudinal, de maneira que cada fragmento fosse constituído por uma parte da região das gemas. A divisão dos 36 tubérculos totalizou 108 fragmentos, os quais foram imersos e imediatamente retirados dos fungicidas, conforme a descrição dos tratamentos. Seis dias após o corte, os fragmentos foram plantados individualmente em vasos com capacidade para $200 \mathrm{~mL}$ de substrato formado por composto orgânico e vermiculita (2:1). O composto orgânico utilizado, produzido pelo Jardim Botânico de Porto Alegre, é à base de folhas e restos vegetais recolhidos na mesma instituição.

Estimou-se a capacidade de cicatrização dos fragmentos por meio da observação visual. O número de novos indivíduos foi avaliado pela observação dos fragmentos não desidratados e pelo desenvolvimento de novas folhas seis meses após o plantio. $\mathrm{O}$ delineamento experimental foi o inteiramente casualizado. Os dados foram submetidos à análise da variância e a comparação das médias, feita pelo teste de Duncan, a 5\% de probabilidade.

\subsection{Estaquia}

Para a avaliação da propagação de $S$. lineata por estaquia, desenvolveu-se um experimento no Laboratório de Biotecnologia do Departamento de Horticultura e Silvicultura da Faculdade de Agronomia da UFRGS. O período experimental foi de setembro a dezembro de 2004. As estacas utilizadas foram retiradas dos tubérculos do experimento anterior e padronizadas ao comprimento médio de $13 \mathrm{~cm}$; mantiveram-se duas folhas em cada estaca. Na parte basal das estacas, realizaram-se duas raspagens laterais e a imersão desta região, durante cinco segundos, em solução hidroalcoólica com AIB. Os tratamentos foram os seguintes: T1 -0 ppm de AIB; T2 100 ppm de AIB; e T3 - 200 ppm de AIB, com 17 repetições para cada um dos tratamentos. As estacas foram plantadas em bandejas de isopor com 72 alvéolos, com substrato formado por casca de arroz carbonizada. A bandeja foi mantida sob nebulização em intervalos de 15 minutos, e ativada por 2 minutos e 30 segundos.

Avaliaram-se, 90 dias após o plantio, os parâmetros número de brotos por estaca, comprimento do broto principal, diâmetro dos tubérculos, comprimento do sistema radicular e massa fresca e seca das raízes. Com os dados procedeu-se a análise de variância, as médias foram submetidas ao teste de Duncan, a 5\% de probabilidade.

\section{RESULTADOS}

\subsection{Divisão de tubérculos}

A tabela 1 apresenta os dados numéricos obtidos no experimento de propagação de $S$. lineata por meio da divisão dos tubérculos.

Os tubérculos de $S$. lineata apresentaram consistência firme, mas de pouca resistência ao seccionamento. A periderme é um tecido membranáceo e de fácil rompimento, de acordo com o observado durante o manuseio dos tubérculos. A coloração esbranquiçada dos tecidos internos tornou-se ferrugínea em poucos segundos, sugerindo sua oxidação.

Os tratamentos propostos neste estudo não apresentaram diferenças em relação à capacidade de cicatrização. Todos os fragmentos dos tubérculos de $S$. lineata cicatrizaram completamente em 24 horas. A rápida capacidade de cicatrização talvez seja uma característica adaptativa ao rolamento de pedras ocorrente em ambientes rupícolas, onde a exposição da região superior dos tubérculos pode ser observada.

Houve a desidratação e a conseqüente inviabilidade de, em média, 75, 100 e 50\% dos fragmentos referentes aos tratamentos 7, 8 e 9 respectivamente (Tabela 1). Nesses tratamentos a divisão dos tubérculos em quatro fragmentos proporcionou a menor massa de tecidos de reserva de nutrientes e água, e maior área exposta para a desidratação, em relação aos demais tratamentos. O plantio realizado logo após a cicatrização poderá evitar a desidratação excessiva e a perda de indivíduos. O substrato utilizado deve ter boa capacidade para retenção de umidade. Seis meses após a secção dos tubérculos, 95\% do total de fragmentos não desidratados (68 indivíduos) já apresentaram dois pares de folhas. Em relação ao total de 108 fragmentos, foram produzidos 72 novos indivíduos 
neste experimento.

\subsection{Estaquia}

Os dados sobre as estacas enraizadas e mortas estão na tabela 2, e aqueles que se referem aos parâmetros avaliados, na tabela 3. A figura 1 ilustra a dispersão dos dados registrados e a ocorrência de alguns valores que se distanciam da média.

Todas as estacas brotaram, e não ocorreu a morte de indivíduos. S. lineata mostrou ser facilmente propagada por estaquia, sem a aplicação de AIB. O substrato e a nebulização utilizados se mostraram eficientes para a propagação por estaquia de $S$. lineata, nas condições experimentais. O presente estudo demonstrou que as estacas de $S$. lineata desenvolveram tubérculos e produziram raízes com facilidade (Tabela 2). Os valores apresentados na tabela 2, com destaque para os dados acerca do desenvolvimento de raízes, indicaram que 90 dias após o início do teste as estacas estavam prontas para serem retiradas da nebulização e plantadas em recipientes.

\section{DISCUSSÃO}

\subsection{Divisão de tubérculos}

Muitas plantas tuberosas são propagadas pela divisão deste órgão de reserva. A Begonia tuberhybrida Voss. X é um exemplo. Eles podem ser cortados em dois, três ou quatro fragmentos, de acordo com o número de gemas que estão localizadas na parte superior. Cada parte cortada deve possuir uma gema que brotará originando uma nova planta (PROPAGAÇÃO, 2006). O yacon (Polymnia sonchifolia Poepp.) é outra espécie que pode ser propagada por meio dos tubérculos, mas que também pode ser propagada por sementes (YACON, 2006). No entanto, o material introduzido no Brasil não tem produzido sementes viáveis, o que valoriza e intensifica a sua propagação via sexuada. A batata-inglesa (Solanum tuberosum L.) é talvez a planta mais conhecida com esta forma de propagação, tradicionalmente praticada pelos camponeses e etnias andinas. Ela pode ser propagada a partir do refugo das safras (as pequenas batatas) ou pelo corte de batatas grandes (SILVA, 1987).

A propagação de $S$. lineata pela divisão de tubérculos foi considerada eficiente neste trabalho. Caso efetue a secção de fragmentos com peso em torno de $20 \mathrm{~g}$, deve-se realizar o cultivo em recipientes logo após a cicatrização para evitar a perda pela desidratação.

\subsection{Estaquia}

Apesar de somente um parâmetro ter apresentado diferença estatística, os dados sugerem um efeito fitotóxico do AIB para as estacas da espécie (tabela 3; figura 3). As temperaturas mais altas dos meses de setembro a dezembro na região sul do Brasil, parece ter influenciado positivamente os resultados. Durante o período experimental, a temperatura média do local foi de $27^{\circ} \mathrm{C}$. De acordo com HARTMANN e KESTER (1968), sob condições apropriadas - como alta umidade e calor, o enraizamento de estacas herbáceas é fácil e atinge altas porcentagens e, mesmo que não necessitem de substâncias para ajudar o enraizamento, são freqüentemente aplicadas para obter uniformidade e abundância de raízes.

Neste estudo, todavia, os tratamentos com AIB também não apresentaram vantagens referentes à uniformidade de enraizamento. Apesar de não ter ocorrido diferença estatística entre a maioria dos parâmetros avaliados dentre os três tratamentos, o tratamento sem AIB apresentou os maiores valores e maior uniformidade em todos os parâmetros avaliados.

Segundo WILSON (1994) e CHUNG e LEE (1994) e KANLESH et al. (1995), citados por WENDLING e XAVIER (2005), as concentrações de regulador de crescimento a serem aplicadas variam em função da espécie, do clone, e do estado de maturação. No entanto, o uso de altas concentrações pode matar a base da estaca, causando excessiva proliferação de células, intensa calosidade ou inibição do crescimento de raízes e da parte aérea (MAHLSTEDE e HABER, 1975 apud SILVA et al., 2004).

As dosagens de AIB testadas em experimentos são variadas justamente pelo desconhecimento da constituição química de muitas espécies vegetais. JUNQUEIRA et al. (2002) testaram 250, 500, 1000 e 2000 ppm em três espécies de Passiflora L.. Os resultados indicaram, com o uso de AIB, incremento no desenvolvimento de raízes e brotos. A melhor dosagem para todas as avaliações para as três espécies foi $1000 \mathrm{ppm}$. O tratamento testemunha foi o que apresentou os menores valores para todos os parâmetros avaliados, e a dosagem mais alta começou a produzir um efeito negativo. Já PEREIRA et al. (1998 apud SIQUEIRA e PEREIRA, 2001) não constataram efeitos significativos do AIB no enraizamento das estacas herbáceas de Passiflora nitida Kunth. Para o enraizamento de estacas folhosas de violetas-africanas (Saintpaulia ionantha $\mathrm{H}$. Wendl.), foram testadas doses bem mais baixas (50, 100 e 200 ppm) por ALVARADO e JESÚS (2001).

A permanência das folhas nas estacas de $S$. lineata parece ter influenciado positivamente a formação de raízes. s o g и п о ( к в а m e r_e KOZLOWSKI, 1960), a presença de folhas nas estacas exerce influência estimuladora sobre o seu enraizamento. Muitos estudos que avaliam as respostas de enraizamento em estacas com e sem folhas têm demonstrado que os melhores resultados são os apresentados por aquelas que permanecem com as folhas. GONTIJO et al. (2006) testaram o enraizamento de aceroleira (Malpighia emarginata Sessé_e Moc. ex DC.) em estacas com um e dois pares de folhas, e sem folhas. Os registros para o número de raízes e a biomassa seca das raízes indicaram resultados superiores para o tratamento com dois pares de folhas. Já as estacas sem folhas não produziram raízes. VENTRELLA (1998) mostrou maiores índices de sobrevivência, enraizamento, número de folhas novas formadas, peso seco e comprimento do sistema radicular em relação às estacas som for a das ostacas d e sa bu g u oiro (Sambucus nigra L.) com folhas inteiras ou folhas cortadas pela metade. Em $S$. lineata, as gemas das estacas são apicais e desprovidas de nós e entrenós na região mediana do caule. No entanto, a influência das folhas para a propagação por estaquia poderá ser avaliada em futuros experimentos, o que não foi possível no presente estudo em função da escassez de material biológico para o preparo de um maior número de 
tratamentos. Com a produção de novos indivíduos por meio dos melhores métodos avaliados pelo presente trabalho, outros estudos poderão testar essa e outras influências sobre a propagação de $S$. lineata pela estaquia.

LAZZARI (1997) admite ser positiva a prática de propagação de espécies nativas pelo método da estaquia, principalmente, se forem utilizadas técnicas como a aplicação de reguladores de crescimento e a nebulização intermitente. Esse mesmo autor também coloca três quesitos que devem ser observados para viabilizar a aplicação comercial desta prática de propagação: facilidade de enraizamento, qualidade do sistema radicular formado e do desenvolvimento posterior da planta na área de produção.

O desenvolvimento de tubérculos e a facilidade para o enraizamento das estacas (tabela 2) demonstraram a rusticidade e a grande capacidade reprodutiva da espécie. Com o desprendimento e rolamento de estacas, estas devem enraizar, iniciar o desenvolvimento do órgão de reserva e se dispersar em outros nichos adequados. Essa capacidade concorda, então, com a rusticidade característica de espécies rupícolas não domesticadas.

Pelos resultados apresentados, pode-se verificar que a espécie demonstrou ser facilmente propagada por meio da divisão dos tubérculos e da estaquia. Os dois métodos experimentados para a propagação vegetativa de S. lineata são de fácil execução, rápida obtenção de novos exemplares e de baixo custo. Aliado a esses fatores, a rusticidade e a notável beleza desta espécie tornam potencialmente viável a sua inclusão no mercado de plantas ornamentais. Esses métodos apresentam grande probabilidade de serem eficientes para a propagação das congêneres de $S$. lineata, todas providas de tubérculos, estacas herbáceas e com potencial ornamental.

É fundamental que a propagação vegetativa de espécies nativas siga critérios que promovam a conservação da variabilidade genética. As matrizes devem ser provenientes de vários pontos na área de distribuição das espécies. Estudos genéticos e o conhecimento das populações das espécies com interesse de multiplicação, seja para fins ornamentais ou conservação ex situ, são necessários para atingir o objetivo de preservação. Caso contrário, a propagação vegetativa não beneficiaria, mas contribuiria para acelerar a erosão genética de espécies ameaçadas.

\section{CONCLUSÃO}

Sinningia lineata (Hjelmq.) Chautems é facilmente propagada por meio da divisão de tubérculos e por estaquia, dispensando a aplicação de fungicidas nos tubérculos seccionados e a utilização de ácido indolbutírico (AIB) para o enraizamento das estacas.

\section{AGRADECIMENTOS}

À CAPES, pelo incentivo à pesquisa e_concessão da bolsa de Mestrado; ao Jardim Botânico de Porto Alegre e aos funcionários Ari Delmo Nilson, Andréia M. Carneiro, Cristina Leonhardt, Geni Teresinha Oliveira, Paulo César Gross (Paulinho) e Geraldo Gonçalves de Araújo (Ceará), pelo apoio e infra-estrutura para a realização do estudo de propagação pela divisão dos tubérculos.

\section{REFERÊNCIAS}

ALVARADO, A.; JESÚS, G. Estudio de la regneración de plantas a partir de estacas de hojas en especies pertenecientes a las familias gesneriaceae, piperaceae y acanthaceae. 2001 . Disponível em: http://150.186.96.57/cgi-win/ be_alex.exe? A c e so=T070500041862/ 0\&Nombrebd=UCLA-AGVET. Acesso em: 03 fev. 2006.

ALVARENGA, L.R.; CARVALHO, V.D. Uso de substâncias promotoras de enraizamento de estacas de frutíferas. Informe Agropecuário, Belo Horizonte, v.9, n.101, p.47-55, 1983.

AVILA, A.C.; BEEK, M.A. Principais viroses: Produção de Batata. Brasília : Linha, 1987. p.103-117.

BACKES, M.A. Composto de lixo urbano como substrato para plantas ornamentais. 78f. 1989. Dissertação (Mestrado) - Programa de Pós-Graduação em Fitotecnia, Faculdade de Agronomia, Universidade Federal do Rio Grande do Sul, Porto Alegre, 1989.

BARROSO, C.M.; CARNEIRO, A.M.; NILSON, A.D.; MONDIN, C.A. Coleções Vivas do Jardim Botânico de Porto Alegre: família Gesneriaceae Nees - dados preliminares. In: ENCONTRO DE BOTÂNICOS DO RIO GRANDE DO SUL, UNIVERSIDADE DE SANTA CRUZ DO SUL, 11., 2002, Santa Cruz do Sul. Anais... Santa Cruz do Sul, 2002. p.63.

BARROSO, C.M.; KLEIN, G.N.; BARROS, I.B.I.; FRANKE, L.B. Considerações sobre a propagação e o uso ornamental de plantas raras ou ameaçadas de extinção no Rio Grande do Sul. In: CONGRESSO BRASILEIRO DE AGROECOLOGIA, 2.; SEMINÁRIO INTERNACIONAL SOBRE AGROECOLOGIA, 5.; SEMINÁRIO ESTADUAL SOBRE AGROECOLOGIA, 6., Porto Alegre, 2004. Resumos... Porto Alegre, 2004. 1CD-Rom

BELLÉ, S. Uso da turfa "Lagoa dos Patos" (Viamão/RS) como substrato hortícola. 142f. 1990. Dissertação (Mestrado) - Programa de Pós-Graduação em Fitotecnia, Faculdade de Agronomia, Universidade Federal do Rio Grande do Sul, Porto Alegre, 1990.

COUVILLON, G.A. Rooting responses to different treatments Acta Horticulturae Wageningen, v.227, p.187196, 1988.

GONTIJO, T.C.A.; RAMOS, J.D.; MENDONÇA, V.; PIO, R.; NETO, S.E.A.; CORRÊA, F.L.O. Concentrações de Ácido Indol-Butírico e Tipos de Estacas na Propagação Vegetativa de Aceroleira. Disponível em: http:// www.ufpel.tche.br/sbfruti/anais_xvii_cbf/propagacao/ 496.htm. Acesso em 03 fev. 2006.

HARTMANN, H.T.; KESTER D.E. Propagacion de 
Plantas: Principios y Prácticas. México: Compañia Editorial Continental, 1968.810p.

HARTMANN, H.T.; KESTER, D.E. Propagacion de Plantas: Principios y Prácticas. México: Compañia Editorial Continental, 1990. 810 p.

IRITANI, C.; SOARES, R.V. Indução do enraizamento de estacas de Araucaria angustifolia através da aplicação de reguladores de crescimento. In: CONGRESSO FLORESTAL BRASILEIRO, 4., 1982, Belo Horizonte. Anais... Belo Horizonte, 1982. p.313-317.

JUNQUEIRA, M.T.V.; CHAVES, R.C.; MANICA, I.; PEIXOTO, J.R.; PEREIRA, A.V.; FIALHO, J.F. Propagação do maracujazeiro-azedo por enxertia em estacas herbáceas enraizadas de espécies de passifloras nativas. Planaltina, DF: Embrapa Cerrados, 2002. Boletim de Pesquisa e Desenvolvimento.

KÄMPF, A.N. Produção comercial de plantas ornamentais. Guaíba: Agropecuária, 2000. 254p.

KRAMER, P.J.; KOZLOWSKI, T.T. Propagação. In: KRAMER, P.J.; KOZLOWSKI, T.T. Fisiologia das árvores. Lisboa: Fundação Calouste Gulbenkian, 1960. cap.13, p.439-475.

LAZZARI,M. Influência da época de coleta, tipos fisiológicos de estaca, boro, zinco e ácido indolbutírico no enraizamento de Platanus acerifolia. 1997. 63f. Dissertação (Mestrado) - Universidade Federal de Santa Maria, Santa Maria, 1997.

PROPAGAÇÃO de flores de vaso. Disponível em: http:// www.uesb.br/flower/propaga.html. Acesso em 03 fev. 2006.

RIO GRANDE DO SUL. Decreto $\mathrm{n}^{\circ} 42.099$ de 31 de dezembro de 2002. Diário Oficial do Estado do Rio Grande do Sul, Porto Alegre, $1^{\circ}$ de janeiro de 2003.

SÃO PAULO. Sinningia lineata (Hjelmq.) Chautems. Disponível em: http://mpeixoto.sites.uol.com.br/ gesneriads/sinningia/lineata.html. Acesso em 28 jan. 2006.
SILVA, L.; PORTO, M.D.M.; KÄMPF， A.N. Características químicas e físicas de substratos à base de turfa e casca de arroz carbonizada. In: KÄMPF, A.N.; FERMINO, M.H. Substrato para Plantas: A Base da Produção Vegetal em Recipientes. Porto Alegre, RS : Gênesis, 2000. p.235-240.

SILVA, J.M.; RAPOSO, A.; SOUSA, J.A.; MIRANDA, E.M. Indução de enraizamento em estacas de joãobrandinho (Piper sp.) com ácido indolbutírico. Revista Ciência Agronômica, Fortaleza, CE, v.35, n. especial, 2004. p. 248-252.

SILVA, R.M. Multiplicação rápida: Produção de Batata. Brasília: Linha Gráfica e Editora, 1987. p.194-210.

SILVEIRA, N.J.E. Gesneriaceae: duas novas ocorrências para o Estado do Rio Grande do Sul. Iheringia, Série Botânica, Porto Alegre, v.42, p.81-85, 1992.

SIQUEIRA, D.L.; PEREIRA, W.E. Propagação. In: BRUCKNER, C.H.; PICANÇO, M.C. (Ed.). Maracujá: tecnologia de produção, pós-colheita, agroindústria, mercado. Porto Alegre: Cinco Continentes, 2001. p.85-137.

STUMPF, E.R.T.; GROLLI, P.R.; SCZEPANSKI, P.H.G. Efeito do ácido indolbutírico, substrato e tipo de estaca no enraizamento de Chamaecyparis lawsoniana Parl. Revista Brasileira de Agrociência, Pelotas, RS, v.7, n.2, 2001. p.101-105.

VENTRELLA, M.C. Efeito das folhas e do tipo de estaca no desenvolvimento do sistema radicular em estacas de s a в и g u . r 。 (Sambucus nigra L.). [S.1.]: Unimar Ciências; 1998. p.7; 1; 81; 85 (Português); p.1415-1642 (Impresso).

WENDLING, I.; XAVIER, A. influência do ácido indolbutírico e da miniestaquia seriada no enraizamento e vigor de miniestacas de clones de Eucalyptus grandis. Árvore: Sociedade de Investigações Florestais, Viçosa, v.29, n.6, 2005. p.921-930.

YACON. Artigo de produto. Saúde na Rede. Disponível em: http://www.saudenarede.com.br/ ?p=av\&id=Yacon. Acesso em 03 fev. 2006. 
Tabela 1. Percentuais médios de fragmentos com cicatrização completa e de fragmentos não desidratados para cada tratamento do teste de multiplicação por tubérculos de Sinningia lineata (Hjelmq.) Chautems

\begin{tabular}{llc}
\hline \multicolumn{1}{c}{ Tratamentos } & Cicatrização completa (\%) & $\begin{array}{c}\text { Fragmentos não desidratados } \\
(\%)\end{array}$ \\
\hline 1. testemunha/2 & $100 \mathbf{a}^{\mathbf{1}}$ & $100 \mathbf{a}$ \\
2. calda bordalesa/2 & $100 \mathbf{a}$ & $100 \mathbf{a}$ \\
3. calda sulfocálcica/2 & $100 \mathbf{a}$ & $100 \mathbf{a}$ \\
4. testemunha/3 & $100 \mathbf{a}$ & $100 \mathbf{a}$ \\
5. calda bordalesa/3 & $100 \mathbf{a}$ & $100 \mathbf{a}$ \\
6. calda sulfocálcica/3 & $100 \mathbf{a}$ & $100 \mathbf{a}$ \\
7. testemunha/4 & $100 \mathbf{a}$ & $025 \mathbf{b}$ \\
8. calda bordalesa/4 & $100 \mathbf{a}$ & $000 \mathbf{b}$ \\
9. calda sulfocálcica/4 & $100 \mathbf{a}$ & 050 b \\
\hline
\end{tabular}

${ }^{1}$ Médias seguidas por letras diferentes na coluna diferem estatisticamente.

Table 1. Fragments percentile mediums with complete cicatrization and of fragments not dehydrated for each treatment of the multiplication test for Sinningia lineata (Hjelmq.) Chautems tubers

\begin{tabular}{lcc}
\multicolumn{1}{c}{ Treatments } & Complete cicatrization (\%) & $\begin{array}{c}\text { Dehydration fragments } \\
(\%)\end{array}$ \\
\hline 1. control/2 & $100 \boldsymbol{a}^{\mathbf{1}}$ & $100 \boldsymbol{a}$ \\
2. bordeaux mixture/2 & $100 \boldsymbol{a}$ & $100 \boldsymbol{a}$ \\
3. sulphur calcium mixture/2 & $100 \boldsymbol{a}$ & $100 \boldsymbol{a}$ \\
4. control/3 & $100 \boldsymbol{a}$ & $100 \boldsymbol{a}$ \\
5. bordeaux mixture/3 & $100 \boldsymbol{a}$ & $100 \boldsymbol{a}$ \\
6. sulphur calcium mixture/3 & $100 \boldsymbol{a}$ & $100 \boldsymbol{a}$ \\
7. control/4 & $100 \boldsymbol{a}$ & $025 \boldsymbol{b}$ \\
8. bordeaux mixture/4 & $100 \boldsymbol{a}$ & $000 \boldsymbol{b}$ \\
9. sulphur calcium mixture/4 & $100 \boldsymbol{a}$ & $050 \boldsymbol{b}$ \\
\hline
\end{tabular}

${ }^{1}$ Means followed by different letters within a column are significantly different. 
Tabela 2. Percentuais de estacas enraizadas e de estacas mortas em cada tratamento do experimento com estaquia de Sinningia lineata (Hjelmq.) Chautems

\begin{tabular}{lcc}
\hline Tratamentos & $\begin{array}{c}\text { Estacas } \\
\text { enraizadas (\%) }\end{array}$ & $\begin{array}{c}\text { Estacas } \\
\text { mortas }(\%)\end{array}$ \\
\hline T1 - 0 ppm & 100 & 0 \\
T2 - 100 ppm & 100 & 0 \\
T3 - 200 ppm & 100 & 0 \\
\hline
\end{tabular}

Table 2. Percentile of rooted cuttings and of cuttings dead in each treatment of the experiment with Sinningia lineata (Hjelmq.) Chautems cutting

\begin{tabular}{lcc}
\hline Treatments & $\begin{array}{c}\text { Rooted } \\
\text { cuttings }(\%)\end{array}$ & $\begin{array}{c}\text { Dead } \\
\text { stems }(\%)\end{array}$ \\
\hline$T 1-0$ ppm & 100 & 0 \\
$T 2-100 \mathrm{ppm}$ & 100 & 0 \\
$T 3-200 \mathrm{ppm}$ & 100 & 0 \\
\hline
\end{tabular}

Tabela 3. Valores médios dos parâmetros avaliados para os três tratamentos do experimento com estaquia de Sinningia lineata (Hjelmq.) Chautems

\begin{tabular}{lccc}
\hline Parâmetros avaliados & $\mathrm{T} 1-0 \mathrm{ppm}$ & $\mathrm{T} 2-100 \mathrm{ppm}$ & $\mathrm{T} 3-200 \mathrm{ppm}$ \\
\hline Número de brotos por estaca & $1,47 \mathbf{A}$ & $1,18 \mathbf{A}$ & $1,35 \mathbf{~ A}$ \\
Comprimento broto principal (cm) & $6,56 \mathbf{A}$ & $4,38 \mathbf{~ B}$ & $3,44 \mathbf{~ B}$ \\
Diâmetro dos tubérculos $(\mathrm{cm})$ & $1,15 \mathbf{A}$ & $1,01 \mathbf{A}$ & $0,95 \mathbf{~ A}$ \\
Comprimento sistema radicular (cm) & $16,41 \mathbf{A}$ & $13,62 \mathbf{A}$ & $15,85 \mathbf{A}$ \\
Massa fresca das raízes $(\mathrm{g})$ & $3,42 \mathbf{A}$ & $3,04 \mathbf{A}$ & $2,12 \mathbf{A}$ \\
Massa seca das raízes $(\mathrm{g})$ & $0,44 \mathbf{A}$ & $0,29 \mathbf{A}$ & $0,24 \mathbf{~ A}$ \\
\hline
\end{tabular}

${ }^{1}$ Médias seguidas por letras diferentes na linha, diferem significativamente pelo teste de Duncan a $5 \%$ de probabilidade.

Table 3. Average values of the parameters evaluated for the three treatments of the experiment with Sinningia lineata (Hjelmq.) Chautems cutting

\begin{tabular}{lccc}
\hline Available parameters & $T 1-0 \mathrm{ppm}$ & $T 2-100 \mathrm{ppm}$ & $T 3-200 \mathrm{ppm}$ \\
\hline Number of sprouts per cutting & $1,47 \boldsymbol{A}$ & $1,18 \boldsymbol{A}$ & $1,35 \boldsymbol{A}$ \\
Principal sprout extension $(\mathrm{cm})$ & $6,56 \boldsymbol{A}$ & $4,38 \boldsymbol{B}$ & $3,44 \boldsymbol{B}$ \\
Diameter of tubers $(\mathrm{cm})$ & $1,15 \boldsymbol{A}$ & $1,01 \boldsymbol{A}$ & $0,95 \boldsymbol{A}$ \\
Root system extension $(\mathrm{cm})$ & $16,41 \boldsymbol{A}$ & $13,62 \boldsymbol{A}$ & $15,85 \boldsymbol{A}$ \\
Root fresh weight $(\mathrm{g})$ & $3,42 \boldsymbol{A}$ & $3,04 \boldsymbol{A}$ & $2,12 \boldsymbol{A}$ \\
Root dry weight $(\mathrm{g})$ & $0,44 \boldsymbol{A}$ & $0,29 \boldsymbol{A}$ & $0,24 \boldsymbol{A}$ \\
\hline
\end{tabular}

${ }^{1}$ Means followed by different letters, on line, are significantly different by Duncan test $(\mathrm{P}<05)$. 